\title{
Requirement for Qualification and Expertise of Nuclear Regulatory Body
}

\section{-To Prevent the Recurrence of the Fukushima Daiichi Nuclear Power Plant Accident-}

\author{
NuFact Associates, Ltd., Toshio Morimoto \\ Tokyo Institute of Technology, Tetsuo Sawada
}

\begin{abstract}
Based on the lessons learned from the accident at the Fukushima Daiichi Nuclear Power Plant in March 2011, the Japanese government is considering the establishment of the Nuclear Safety Agency as an external bureau of the Ministry of Environment. Changes in the formation of the nuclear regulatory agency are not urgent in Japan. Urgent matters are challenges related to internal matters, especially the improvement of the expertise of its senior managers. It is necessary to appoint the director general and senior managers of the Nuclear Safety Agency based on their competencies and to establish their tenure at a level similar to that in the European and American countries. Receiving the IAEA review again will also be effective to upgrade the nuclear safety regulations of Japan to the international level.
\end{abstract}

\section{Lessons from SKI in Sweden}

\section{Unexpected Phenomenon at Barsebäck Nuclear Power Plant}

In July 1992, a safety relief valve was inadvertently opened due to an event at the Barsebäck Nuclear Power Plant. The ejected steam broke the insulator, which led to partial blockage of the strainer on the inlet of emergency reactor cooling pump. At that time, the occurrence and the results of such a phenomenon were not considered in safety review of nuclear power plants in any country.

However, the director of SKI (the Swedish nuclear regulatory agency at that time), who had implemented the safety review for construction of the plant, seriously considered the failure to address such a possibility previously and made a strong request to the Swedish government for the review of the competency of SKI by an international committee. As a result, the Swedish government convened domestic and international experts and formed a review team to identify deficiencies regarding the safety review capability of SKI. The appointed team members included the former executives of NRC, individuals involved in nuclear regulations in countries such as France and Finland, and those in aircraft safety review in Sweden. The

DOI : 10.15669/fukushimainsights.Vol.1.168

(C) 2021 Atomic Energy Society of Japan. All rights reserved.

Originally published in Journal of the Atomic Energy Society of Japan (ISSN 1882-2606), Vol. 53, No. 12, p. 826-830

(2011) in Japanese. (Japanese version accepted: October 15, 2011) 
review was conducted from 1994 to 1995 and pointed out that "though the regulatory activities of SKI are of high quality and are appropriate, there exist many undocumented procedures." This led to the development of the quality management system (QMS) of SKI.

\section{Lessons from Sweden}

The phenomenon in Barsebäck did not lead to a disaster. However, the director of SKI seriously took the insufficient review, received an external review on its review capability, and implemented the given advices. Japanese government should take a leaf from Swedish style mentioned above that the executive took the lead in humbly learning these lessons and implementing improvements.

Japan's Nuclear and Industrial Safety Agency (NISA), the nuclear regulatory agency, received IAEA's Integrated Regulatory Review Service (IRRS) with regard to its regulatory systems in $2007^{1)}$. However, the scope of the review was limited and the follow-up review by IAEA has not applied by Japanese government yet. Humbly receiving IAEA's review on nuclear safety regulations under the governance of the Nuclear Safety Agency is an international obligation as well as the foundation for restoration of trust.

\section{Lessons for Japan}

The main cause of the accident at the Fukushima Daiichi Nuclear Power Plant (Fukushima Accident) in March 2011 was the insufficient postulations of tsunamis and station blackouts (SBOs). The prime responsibility to maintain the safety of nuclear power plants within the licensed conditions rests with the operators. However, the responsibility to determine and revise the licensed conditions must rest with the regulatory agency, NISA. Therefore, the authors think that in-depth but primary responsibility for the Fukushima Accident mainly attributed for the Japanese regulatory agency. It is possible to argue that Tokyo Electric Power Company (TEPCO) also had a responsibility based on the current laws. However, honest self-reviews based on objective facts by regulatory agencies, especially NISA, are required. Furthermore, the insufficient recognition of issues by the Nuclear Safety Commission, an advisory agency, should not be overlooked. The agency had poor recognition of safety important issues and failed to provide clear directions to NISA on matters such as SBO.

We assume there are at least three root causes of the Fukushima Accident, as follows.

(1) Delayed Action on New Regulatory Issues: There was no clear regulatory position in Japan with regard to matters, such as the predicted level of tsunamis and protective measures for safety systems and buildings in the case of site flooding. Even if NISA had definitely determined its position on tsunamis based on recent knowledge about tsunami and countermeasures against tsunami taken in foreign countries, it is not clear whether the tsunami at Fukushima site of this time was postulated and whether effective measures were taken in place. In Japan, actions against new regulatory issues were often delayed. The speedup of such actions is crucial now more than ever. If this improper regulatory attitude is not improved, the trust in the regulations will not be restored in Japan. When there were only a few nuclear power plants in Japan, it might be inevitable that regulatory actions were taken based on individual basis. However, currently, there are more than 50 rectors in Japan and it is indispensable for Japanese regulatory agency to present regulatory policies on generic basis for each unresolved regulatory issues to ensure stable regulation and establish a consensus among 
the people.

(2) Delayed Periodic Review of Existing Guides for Safety Regulations: In Japan, the Regulatory Guide for Reviewing Safety Design of Light Water Nuclear Power Plants was revised in 1977 to consider short term (approximately 30-min) SBOs. Later, in 1988, in the U.S, longer term SBOs were required and all nuclear power plants in the country became capable to endure SBOs longer than $4 \mathrm{hr}$. After that, in Japan, the suitability of regulatory requirements of SBO endurance time was discussed, but considering the high levels of reliability of off-site power supplies in Japan, among others, SBO endurance time was not revised, and consideration of extended SBOs was left as a voluntary action of electric power companies.

Later, the importance of the SBO measures to prevent core damage was recognized around the world, and IAEA stated in its guide for the design of emergency power systems ${ }^{2)}$ that the possibility of SBO should be taken into consideration, even with high levels of off-site power and emergency power supplies (clause 2.14).

The Fukushima Accident may not have been prevented even if the measures for extended SBO were formally required and not left as voluntary actions. However, suitable operator actions against the SBO at Fukushima Daiichi Nuclear Power Plant could have been more secure.

A system for periodic revision of established safety regulation guidelines could have brought NISA to stricter regulation on SBO. This could have in turn led to more appropriate inspections of accident management procedures for SBO.

(3) Lack of a Formal Review Process for Differing Professional Opinions: With regard to the current postulated tsunami conditions, it has been said that some experts raised objections. If NISA had a formal process to review differing opinions expressed by experts of nuclear safety regulations, it could have led to a prompt revision of the design conditions for tsunamis.

\section{Future Regulatory Actions}

This chapter proposes corrective actions to eliminate the three root causes discussed in Chapter II, considering good practices in foreign countries.

\section{Systematic Approach to New Regulatory Issues}

According to an IAEA guide for regulatory review (clause 3.24), regulatory agencies are required to collect information from a broad range, including operational experience at nuclear power plants and results of research and development ${ }^{3)}$, when they are trying to establish regulatory requirements. In Japan, similar to other countries, the regulatory agency, NISA, collected various types of information, including the current activities of regulatory organizations in foreign countries, and reviewed them. However, the collection and review have largely relied on the individual efforts of NISA staff and were not systematically organized by NISA.

As occurred in the US after the Three Mile Island Nuclear Plant (TMI) Accident, in Japan, after the Fukushima Accident, many safety related countermeasures will be proposed. The importance of such countermeasures will vary widely and many of them would have overlapping effects. The US NRC developed Generic Issues Program (GIP) that systematically consolidated new safety issues with old unresolved safety issues that were identified prior to the 
TMI Accident. In this program, NRC prioritized these issues based on the safety benefit and cost of each issue, and gradually established regulatory policy or position of each issue ${ }^{4)}$. In GIP, NRC staff project teams are founded for important safety issues. From the initial stages of projects, these teams involved staff in charge of legal issue. The review status of GIP was periodically reported to the US Congress. It would be helpful for Japanese nuclear regulatory agency to learn good practices of project-based approach, which would avoid adverse impact of frequent staff shift, and to learn the merit of legal staff involvement from the initial stages in the project team. It would be also important for the agency to report the status of each project to the Diet periodically, in order to ensure the continuous progress of each project.

\section{Periodic Review of Existing Regulatory Requirements}

It is necessary to review the existing regulatory requirements based on the operational experience and new knowledge. In the US, NRC has set numerous regulatory guidelines, which are basically reviewed every five years ${ }^{5)}$. Periodic review of existing safety regulations is indispensable to ensure that they are effective and reasonable. In Japan, NISA did not have such a periodic review system formally. It preserved old requirements if they did not conflict with new requirements. It was lazy and wrong attitude for sound regulations. Periodic review of existing regulatory requirements is crucial to the scrap-and-build of existing regulatory requirements. Blind increase of safety requirements by nuclear regulatory agency causes unnecessary burdens on the staff of nuclear power plants, decreases their trust in the regulatory requirements, and finally degrades the safety culture at the plants. The staff of the nuclear safety regulatory administration should engrave on their heart and never forget this harmful effect to the safety culture at nuclear power plants.

\section{Establishment of Formal Process to Review professional Differing Opinions}

In the US, NRC has an official process to discuss and consider professional opinions of NRC staff differing from current NRC regulations ${ }^{6}$. NRC staff who have differing opinions first submit his or her differing professional opinion (DPO) to the director of office of the submitter via a written document, upon which a DPO review panel directed by the director reviews the validity and acceptability of the DPO. If the submitter is not satisfied with the review result, he/she can submit the DPO to the NRC committee or the Executive Director for Operations and the DPO is examined again. The result of reviews is made public upon the submitter's request. In DPO document, a submitter is required to describe the differences between his or her opinion and NRC's regulation as well as the supposed consequences in cases wherein his or her opinions are not accepted. One of the criterion to acknowledge a DPO as professional opinion is that it must not be based on a shallow consideration.

The nuclear safety assessment requires a high level of expertise, and there might be disagreements among the experts. Even when the experts' opinions are not uniform, the regulatory agency often has to make administrative decisions. In such cases, it is important to accumulate the arguments related to and the rationale for the administrative decision, for the sake of stability and transparency of the regulations. The Japanese nuclear regulatory agency should learn good practices from NRC regarding this point. In addition, administrative decisions have to be made based on legal grounds. Therefore, it is urgent for Japanese nuclear regulatory agency to establish a concrete regulatory framework for safety goals that will bring basis for nuclear safety regulations. 


\section{Acquisition of Human Resources}

\section{Expected Competency}

The corrective actions discussed in Chapter III pertain to regulatory policies and require continuous efforts to be made. The director and full-time executives of the regulatory agency play important roles in implementing the actions, and they must have sufficient expertise to carry out their duties. Expert knowledge regarding nuclear safety is a prerequisite for those who work on nuclear safety regulation, however, mere knowledge is insufficient. It is important for them to have sound personalities as well as leadership with regard to solving problems and competency in terms of management.

SKI in Sweden evaluates the competency of the staff based on the following five points ${ }^{7)}$ :

Expertise: Expertise in nuclear reactor physics, hydrothermal dynamics, PSA, etc.

Individuality: Ethical judgment, creativity, strong sense of responsibility, etc.

Sociability: Cooperation with colleagues, ability to form networks, etc.

Strategic characteristics: Ability to make decisions with holistic and long-term perspectives Functionality: Ability to execute duties reflecting multiple dimensions altogether

Among these points, expertise is the most important, while the remaining four are considered to be supplementary. SKI staff is required to have the above characteristics, and the higher the position one has, the higher the level of such characteristics one is expected to possess. Director of offices are required to have ${ }^{7)}$

(a) Good knowledge and experience in the field of nuclear safety : Competency not only with regard to technical aspects but also as a generalist who works with people and organizations.

(b) Knowledge about how government authorities function.

(c) Knowledge about international developments in the field of nuclear safety.

(d) Good performance as a manager and leader of scientifically/technically highly competent professionals.

In addition, desirable leadership competencies include the following:

- Ability to motivate and provide feedback to staff,

- Make use of and develop staff competence,

- Administrative skills such as planning, prioritizing, and evaluation,

- Ability to develop holistic views and see long-term strategic perspectives,

- Analytical skills,

- Sound judgment, inspiring confidence, possessing a high degree of personal integrity, non-pretentious,

- Ability to make decisions based on facts and without unnecessary delay.

There are few who meet all of the above criteria; the weak points are communicated to the directors as room for improvement, when they are appointed.

\section{Relationship with Advisory Agencies}

IAEA has the following requirements regarding the relationship between the regulatory agency and advisory agency and/or external consultants ${ }^{8)}$.

"The regulatory body must have experienced experts who can evaluate the quality and results of work done by external consultants" (clause 4.3).

"The regulatory body shall not solely depend on safety evaluations by external experts and other evaluations by private companies. Therefore, the regulatory body shall have full-time 
staff capable of either performing reviews and evaluations according with regulations or evaluating the appropriateness of the evaluations performed by external experts" (clause 4.8).

IAEA also requires that advisory agencies and technical support organizations shall not relieve the regulatory body of its responsibility for making decisions ${ }^{8)}$ (clause 4.4 and 4.9).

To compensate the poor expertise in the Japanese regulatory agency, Japanese government appointed many university academics for Nuclear Safety Commission (NSC) and for various nuclear safety related advisory committees, and accepted recommendations from them. In the safety review by NISA, usually, most of them directly depended ${ }^{9)}$ on various NSC's guides that were prepared by NSC for its safety reviews independently performed from NISA. This curious situation is partially due to some historical matters. The authors do not know such inefficient safety review process in the European and American countries. To make more efficient, and timely decisions, and to improve the ability to explain its decisions for public, the regulatory agency of Japan should increase the number of full-time staff who have sophisticated expert knowledge with regard to nuclear safety.

\section{Tenure and Appointment Process of the Executives}

To implement the corrective actions discussed in Chapter III steadily with a consistent policy, Japanese nuclear regulatory agency should avoid frequent changes of its director general. In the IAEA requirements or guides, there is no particular provision regarding the appointment of the director general of the regulatory agency. The following are the current regulations about the appointment of director generals of regulatory agencies in the European and American countries.

\begin{tabular}{|c|c|c|c|}
\hline $\begin{array}{l}\text { Agency/ } \\
\text { Country }\end{array}$ & $\begin{array}{l}\text { Director } \\
\text { General }\end{array}$ & Tenure & Number \\
\hline NRC U.S. & $\begin{array}{l}\text { NRC } \\
\text { Committee }\end{array}$ & 5 years & $\begin{array}{l}\text { In total, five members are appointed by the President with an agreement } \\
\text { with Congress. }\end{array}$ \\
\hline ASN France & $\begin{array}{l}\text { ASN } \\
\text { Council }\end{array}$ & 6 years & $\begin{array}{l}\text { In total, five members, three members are appointed by President, one by } \\
\text { National Assembly chairman, and one by Senate President. }\end{array}$ \\
\hline STUK Finland & Director & Life-long* & *Until age 67. \\
\hline SKI Sweden & Director & $\begin{array}{l}7 \text { years } \\
\text { (avg.) }\end{array}$ & $\begin{array}{l}\text { Highest decision-making body is the board of trustees consisting of eight } \\
\text { members. Chairman is the SKI director. In } 2005 \text {, three were members of } \\
\text { Congress, of which one was supreme court judge. Average term of board } \\
\text { members is } \sim 6 \text { years. }\end{array}$ \\
\hline
\end{tabular}

Executives of these countries stay for a long term. On the contrary, the director generals of the NISA, the Japanese nuclear regulatory agency, changed frequently as follows;

\begin{tabular}{|c|c|r|}
\hline Succession & Name & \multicolumn{1}{c|}{ Appointed } \\
\hline 1st & Yoshihiko SASAKI & January 2001 \\
\hline 2nd & Kazuo MATSUNAGA & June 2004 \\
\hline 3rd & Kenkichi HIROSE & September 2005 \\
\hline 4th & Yasuhisa KOMODA & July 2007 \\
\hline 5th & Nobuaki TERASAKA & July 2009 \\
\hline 6th & Hiroyuki FUKANO & August 2011 \\
\hline
\end{tabular}

As can be seen above, the director generals of NISA were replaced approximately every two years, which is a great difference from the cycle in European and American countries. Japan, which needs to quickly catch up with international standards with regard to safety 
regulations, can no longer allow the repetition of such a short-term cycle for executives in regulatory agencies.

Currently, the government is planning to abolish NISA and establish the Nuclear Safety Agency as an external bureau of the Ministry of Environment (MOE). Director general of external bureaus is usually appointed by the minister of the corresponding ministry, in Japan. To ensure political neutrality and stability, the appointment of director general of the Nuclear Safety Agency should be approved by the National Diet, and a board of directors (or a council) should be created within the agency to support the director general, similar to nuclear regulatory agencies in France and Sweden.

\section{Appointment Process for Chief Managers}

The chief managers of U.S. NRC, such as the director of NRR (Office of Nuclear Reactor Regulation), are appointed by the chairman of the NRC commission with the agreement of the commission ${ }^{10)}$. According to our survey taken in 2005, the term in office of the previous four directors of NRR ranged from 3 to 7 years; and all of them had more than 20 years of experience in the field of nuclear safety ${ }^{7}$.

To execute the corrective actions discussed in Chapter III in a stable manner, it is necessary to appoint appropriately competent individuals as chief managers of the Nuclear Safety Agency, and they should stay in their positions for at least five years. To this end, the term in office of the director general or the chairman who has a power to appoint chief managers, also should be more than five years, as in the case of European and American countries. The appointment of chief managers should not be rotated according to mere formality.

\section{Implementation of Direct Hiring by the Nuclear Safety Agency}

An IAEA safety guide ${ }^{11)}$ recommends that "the regulatory agency should have the responsibility and authority to recruit staff with technical expertise" (clause 2.9). The regulatory agencies in the U.S., Sweden, and Finland directly hire individuals who seek to work in nuclear safety regulations. As external bureaus are authorized to hire competent staff by themselves directly, the Nuclear Safety Agency should hire its staff directly from those who passed the civil service examination and not to select staff from persons who are hired by the MOE. This should be a basic policy for preservation and improvement of its expertise. People who are hired by the MOE may not want to engage in nuclear safety regulations. Appointing staff from such people is not only undesirable in terms of the development of expertise at the Nuclear Safety Agency but also leave the staff unfulfilled.

\section{Preventing Expert Staff from Outflowing to Other Agencies}

Many members of the NISA would move to the new Nuclear Safety Agency to maintain the continuation and consistency of regulatory administration. It is inevitable that some of them, particularly those who do not seek to become experts in nuclear safety regulations, will return to their mother ministries, e.g., the Ministry of Economy, Trade and Industry (METI). IAEA requires the nuclear regulatory agency to be effectively independent from organizations and groups that promote nuclear technology ${ }^{8)}$ (clause 2.2). To maintain and improve the expertise of the staff of the Nuclear Safety Agency and to meet IAEA requirements, the managers of the Nuclear Safety Agency should not be hired from other ministries or agencies. 
In general, supplementation of the managerial staff must be done within the Nuclear Safety Agency. In addition, it is important not to allow the staff members in managerial positions to return to their mother organizations, in general.

Such a rule, i.e., the no-return rule, was applied between the Financial Control Agency (now the Financial Services Agency) and the Ministry of Finance based on the "principle of separation of finance and fiscal" when the former was established. This time, based on the "principle of separation of nuclear safety regulation and development," such a rule should be placed between the Nuclear Safety Agency and nuclear promoting ministries such as METI.

\section{Acquiring Human Resources from the Private Sector}

Direct hiring and development of those who passed the civil service examination is fundamental, but it should be necessary to hire experts from the private sector without requirement of passing the examinations to acquire experts immediately. Such unusual employment is allowed by the Article 36 of National Public Service Act, and ruled in detail by National Personnel Authority's rule 1-24 Special cases of employment of human resources from the private sector for the development of official affairs. In addition, the Act on Special Measures of Employment and Remuneration of Officials with Fixed Term of Office in the Regular Service would be useful to proceed such employment. It should be important for the Nuclear Safety Agency to employ experts from private sectors, applying these acts and rules. And in such cases, it is important to eliminate the discrimination between those who passed the civil service examination and those who did not, and to assign experts from private sectors to the position of chief managers based on their competencies. This should be necessary to secure human resources of the agency and vitalize it.

\section{Establishment of a QMS of the Nuclear Safety Agency}

To ensure the progress of corrective actions discussed in Chapters III and IV, it is important for the Nuclear Safety Agency to establish and implement a quality management system (QMS). In the QMS, the mission of the Nuclear Safety Agency will be described in detail and the strategies to achieve the missions and the policy to secure and improve necessary human resources will be determined. Self-assessment and third-party assessment of the implemented status are required, and necessary corrective actions will be implemented. IAEA also requires regulatory agencies to establish QMS in its safety guide ${ }^{11)}$ (clause 3.9).

Upon the review by IAEA in 2007, NISA received advice from IAEA with regard to the continuation of NISA efforts to establish QMS ${ }^{1)}$. (Recommendation R10). The establishment and implementation of QMS by the Nuclear Safety Agency is one of the necessary conditions for bringing the level of Japanese nuclear safety regulations to the international level.

\section{Comprehensive Review by IAEA}

As discussed in Chapters I and V, NISA received Integrated Regulatory Review Service (IRRS) by IAEA in 2007, but its scope was limited, and the follow-up review is not yet applied by Japanese government. This should have earned frowns from the member countries of IAEA and increased the mistrust in nuclear safety regulations of Japan. Following the case in 
Sweden discussed in Chapter I, the Nuclear Safety Agency and its staff should be humble and indispensably apply IAEA for the follow-up review of IRRS.

\section{Conclusions}

Today, Japanese government is considering to establish the Nuclear Safety Agency as an external bureau of the MOE to improve nuclear safety regulations. From the viewpoint of the separation of regulation and development of nuclear industry, this organizational change is important, but more important is to improve the level of expertise and the quality of it. Even if the organizational framework is renewed, a personnel system based on loaned employment from other government organizations and short term periodic shifting of personnel will impair the efforts to obtain sufficient expertise of the executives of the renewed regulatory agency. The nuclear regulatory agencies in European and American countries have high levels of expertise of executive staff, and it is rare to rely on external experts to make expert decisions. The principle of nuclear safety regulations in Japan is to "no hindrance to the prevention of the hazard by reactors etc.," but there are no specific developments or interpretations of this vague principle. The new Nuclear Safety Agency should establish concrete safety principles such as safety goals, and make administrative decisions on individual safety issues based on expertise of its own staff. It would be a fundamental matter to improve the stability, timeliness, efficiency, and transparency of Japanese safety regulations.

This commentary was written with a hope that it could be useful for the government's discussions to establish the new Nuclear Safety Agency. There should be some assertions that do not have firm arguments. The authors would appreciate any comments and opinions of the readers in this regard.

\section{References}

1) INTERNATIONAL ATOMIC ENERGY AGENCY, Integrated Regulatory Review Service (IRRS) to Japan, IAEA-NSNI-IRRS-2007/01, IAEA, Vienna (2007).

2) INTERNATIONAL ATOMIC ENERGY AGENCY, Design of Emergency Power Systems for Nuclear Power Plants, IAEA Safety Standards Series No. NS-G-1.8, IAEA, Vienna (2004).

3) INTERNATIONAL ATOMIC ENERGY AGENCY, Review and Assessment of Nuclear Facilities by the Regulatory Body, Safety Standards Series No. GS-G-1.2, IAEA, Vienna (2002).

4) U.S. Nuclear Regulatory Commission, Generic Issues Program, NRC Management Directives MD 6.4, Washington, D. C. (2009).

5) U.S. Nuclear Regulatory Commission, Regulatory Guides, Management Directives MD 6.6, Washington, D. C. (2011).

6) U.S. Nuclear Regulatory Commission, Differing Professional Views or Opinions, Management Directives MD 10.159, Washington, D. C. (1999).

7) Sawada T. et al., Study on the methods to evaluate the value of whistle-blowing in nuclear power plants. (Final report), Japan Nuclear Energy Safety Organization (2006). [in Japanese]

8) INTERNATIONAL ATOMIC ENERGY AGENCY, Legal and Governmental Infrastructure for Nuclear, Radiation, Radioactive Waste and Transport Safety, Safety Standards Series No. GS-R-1, IAEA, Vienna (2000).

9) Nuclear and Industrial Safety Agency, Internal manual for safety review for the construction permit of nuclear reactor installation. Tokyo (2006). [in Japanese]

10) U.S. Federal Government, Energy Reorganization Act of 1974, Washington, D. C. (1974).

11) INTERNATIONAL ATOMIC ENERGY AGENCY, Organization and Staffing of the Regulatory Body for Nuclear Facilities, Safety Standards Series No. GS-G-1.1, IAEA, Vienna (2002). 